\title{
HUBUNGAN MOTIVASI BERPRESTASI DAN PERHATIAN TERHADAP PROSES KOGNITIF PADA MAHASISWA TAHUN PERTAMA JURUSAN KESEHATAN LINGKUNGAN POLITEKNIK KESEHATAN MALUKU
}

\author{
Nurlaila Marasabessy*, Yayi Suryo Prabandari**, Ova Emilia** \\ *Politeknik Kesehatan Departemen Kesehatan Maluku, Ambon \\ ** Fakultas Kedokteran Universitas Gadjah Mada, Yogyakarta
}

\begin{abstract}
Background: Earlier data showed that the mean of achievement index at first year students in Environmental Health Polytechnic of Maluku were decreased for the last 3 years, from 2,9 at year 2008, become 2,6 at year 2010. Students presence rate in the first semester for science and skills subjects such as basic of environmental health, microbiology, patophysio-anatomy, and health entomology also decreased from 89,09\% at 2008 to $77,04 \%$ at 2010. Several studies and experts concludes that both quality and quantity of student's learning are influenced by some factors like achievement motivation, attention, and cognitive process. The decrease on that factors may influence quality and quantity of learning process. The objective of this study is to identify the correlations between achievement motivation and attention to student's cognitive process at first year students of Environmental Health Polytechnic of Maluku.

Method: This was a quantitative study using survey to 80 first year students academic year 2010/2011. It is used modified instrument Archer's Health Professional Motivation Survey to assess achievement motivation, Attention Deficit/ Hyperactivity Disorder to assess attention, and Cognitive Processing Inventory to assess cognitive process. Correlation significance between factors analyzed by using Pearson Correlation.

Results: There were significant correlations between achievement-motivation oriented to mastery learning and performance towards cognitive process. Attention factor also correlated to the cognitive process.

Conclusion: Early stimulations of learning motivation and profession explanation are needed to the first year students. Learning methods that stimulate students engagement are important to improve the quality of student's learning process.
\end{abstract}

Keywords: achievement motivation, attention, cognitive process

\section{ABSTRAK}

Latar Belakang: Data awal terkait prestasi belajar mahasiswa tahun pertama di Jurusan Kesehatan Lingkungan Politeknik Kesehatan Maluku, memperlihatkan penurunan rerata indeks prestasi selama 3 tahun berturut-turut dari 2,9 di tahun 2008, menjadi 2,6 di tahun 2010. Rerata tingkat kehadiran mahasiswa semester 1 untuk mata kuliah keilmuan dan keterampilan seperti, dasar kesehatan lingkungan, mikrobiologi lingkungan, patofisioanatomi, dan entomologi kesehatan juga mengalami penurunan dari 89,09\% di tahun 2008 menjadi 77,04\% di tahun 2010. Beberapa penelitian maupun pendapat ahli mengemukakan bahwa proses belajar dipengaruhi beberapa faktor, diantaranya motivasi berprestasi, perhatian, dan proses kognitif, sehingga penurunan faktorfaktor tersebut tentunya akan mempengaruhi kuantitas dan kualitas proses belajar. Penelitian ini bertujuan untuk mengidentifikasi hubungan faktor motivasi berprestasi dan perhatian dengan proses kognitif pada mahasiswa tahun pertama Jurusan Kesehatan Lingkungan Politeknik Kesehatan Maluku.

Metode: Desain penelitian menggunakan studi kuantitatif dengan jenis penelitian survey yang dilakukan pada 80 mahasiswa tingkat I tahun akademik 2010/2011. Penilaian menggunakan modifikasi instrumen Archer's Health

Korespondensi: nurlailaahmad@rocketmail.com Telp. 0911-362945,

Politeknik Kesehatan Departemen Kesehatan Maluku

Jl. Laksda Leo Wattimena-Kompleks RSJ Negeri Lama, Ambon 97233 
Professional Motivation Survey untuk mengukur motivasi berprestasi, Attention Deficit/Hyperactivity Disorder untuk mengukur perhatian, dan Cognitive Processing Inventory untuk mengukur proses kognitif. Signifikansi hubungan antar faktor dianalisis menggunakan uji korelasi Pearson.

Hasil: Hasil analisis menunjukkan adanya hubungan yang signifikan antara motivasi berprestasi yang berorientasi pada belajar tuntas dan penampilan dengan proses kognitif, demikian pula halnya dengan faktor

Kesimpulan: Perlu adanya rangsangan motivasi belajar kepada mahasiswa di awal pendidikan serta penjelasan kompetensi profesi, selain itu perlu adanya metode belajar yang memicu adanya keterlibatan mahasiswa.

Kata kunci: motivasi berprestasi, perhatian, proses kognitif.

\section{PENDAHULUAN}

Jurusan Kesehatan Lingkungan Politeknik Kesehatan Maluku dalam proses belajar mengajar yang dilakukan selama ini, masih mengacu padametode pembelajaran yang berpusat pada peran pengajar dalam proses belajar (teacher-centered learning). Salah satu hambatan yang kemudian muncul terkait dengan proses pembelajaran tersebut adalah ketika mahasiswa melupakan materi kompetensi dasar yang telah dipelajarinya pada semester awal, baik yang merupakan kompetensi kritis maupun non-kritis. Hal ini umumnya terjadi pada mahasiswa tingkat lanjut. Pada saat ujian komprehensif di tingkat akhir sebagian besar penguji menilai bahwa mahasiswa tidak dapat menjawab pertanyaan-pertanyaan dasar terkait dengan kompetensi yang harus dimiliki. Kasus lain adalah dengan dilakukannya penyegaran untuk beberapa mata kuliah. Hal ini dilakukan sebelum mahasiswa melakukan praktek lapangan atau pada saat akan menyusun karya tulis ilmiah, seperti yang terjadi pada pertemuan tingkat jurusan tanggal 18 Januari 2010. Pada pertemuan tersebut telah disepakati bersama bahwa mahasiswa tingkat III (semester 6) yang akan menjalani proses penyusunan karya tulis ilmiah, agar mempelajari kembali mata kuliah metodologi penelitian, padahal mata kuliah tersebut telah mereka dapatkan di semester 5.

Masalah penurunan pengetahuan atau knowledge loss ini tentunya perlu mendapat perhatian serius dari pengelola pendidikan. Penurunan pengetahuan yang terjadi masih terkait dengan kualitas maupun kuantitas pembelajaran awal yang dialami mahasiswa, sehingga dengan memperbaiki kualitas dan kuantitas pembelajaran diharapkan dapat membantu mahasiswa dalam membentuk pengetahuan (knowledge building) dan menyimpan pengetahuan (knowledge storage) yang dimilikinya, baik dalam memori jangka pendek maupun jangka panjang. ${ }^{1}$

Dalam kaitannya dengan kualitas dan kuantitas pembelajaran, terdapat banyak faktor yang berperan didalamnya. Beberapa faktor utamanya adalah motivasi, perhatian, dan proses kognitif yang dialami oleh mahasiswa selama proses belajar tersebut dilakukan. Terkait dengan peranan ketiga faktor tersebut dalam proses belajar, beberapa pendapat telah dikemukakan oleh para ahli pendidikan, diantaranya adalah, pendapat Huitt ${ }^{2}$ bahwa salah satu kebutuhan yang memacu adanya motivasi dalam melakukan sesuatu adalah kebutuhan kognitif, dan sumber dari kebutuhan kognitif tersebut di antaranya adalah dengan memberikan perhatian (attention) khusus terhadap hal-hal yang sifatnya menarik serta menantang. Menurut Suprijanto, ${ }^{3}$ proses belajar yang dialami oleh individu diawali dengan adanya motivasi dan perhatian, sedangkan menurut pendapat lain oleh Alschuler et al. (cit. Elias dan Rahman), ${ }^{4}$ pengembangan performa, baik sikap mahasiswa maupun pendidikan itu sendiri masih terkait dengan pengembangan motivasi dalam berprestasi. Robbins (cit. Perrot et al. $)^{5}$ mengemukakan bahwa pembelajaran aktif, bebas, dan mandiri (self-directed learning) membutuhkan motivasi dari mahasiswa itu sendiri. Terkait dengan pendapat Robbins tersebut, dalampenelitian yang dilakukan oleh Perrot et al., ${ }^{5}$ dari 252 mahasiswa profesi kesehatan di Mid-Southern Health Science Campus, University of Arkansas, 63\% mahasiswa memiliki motivasi berprestasi yang berorientasi pada pembelajaran tuntas (mastery learning) dan motivasi mereka tersebut sebagian besar (88\%) muncul dari dalam diri mahasiswa itu sendiri (internal locus of control).

Hasil observasi awal yang dilakukan oleh peneliti memperlihatkan bahwa mahasiswa di Jurusan Kesehatan 
Lingkungan Politeknik Kesehatan Maluku masih memiliki motivasi yang rendah dalam belajar, hal ini terlihat pada rerata Indeks Prestasi (IP) mahasiswa semester 1, selama 3 tahun berturut-turut mengalami penurunan dari rerata IP 2,9 pada tahun 2008, turun menjadi 2,6 pada tahun 2010. Selain itu rerata tingkat kehadiran mahasiswa di setiap semester 1 untuk mata kuliah keilmuan dan keterampilan (MKK) seperti dasar kesehatan lingkungan (DKL), mikrobiologi lingkungan, patofisioanatomi, dan entomologi kesehatan, juga mengalami penurunan dari $89,09 \%$ di tahun 2008

menjadi 77,04\% di tahun 2010.

Serupa dengan motivasi, proses belajar juga membutuhkan adanya perhatian (attention). Mengutip pendapat yang telah disebutkan sebelumnya oleh Suprijanto, ${ }^{3}$ selain motivasi, proses belajar juga diawali dengan adanya perhatian. Mahasiswa harus dapat memusatkan perhatiannya pada materi yang diajarkan. Apabila hal tersebut tidak terjadi, maka proses kognitif akan mengalami hambatan. Berdasarkan hasil observasi awal serta pengalaman dari peneliti sendiri menemukan bahwa tingkat kedisiplinan mahasiswa dalam belajar masih kurang, misalnya, terdapat mahasiswa yang melakukan aktivitas lain di luar konten belajar saat perkuliahan berlangsung, atau ketidakdisiplinan waktu dalammenyelesaikan tugas-tugas kuliah yang diberikan. Masalah ini tentunya akan berpengaruh terhadap proses kognitif mahasiswa selama proses belajar dilakukan. Jiang $\&$ Chun $^{6}$ mengemukakan bahwa perhatian dan belajar merupakan 2 hal fundamental dalam proses visual manusia. Dengan memberikan perhatian secara intens dan selektif, mahasiswa akan lebih mengarahkan dirinya pada penerimaan informasi yang relevan, bukan sebaliknya, mengindahkan informasi yang tidak relevan.

Motivasi untuk berprestasi serta perhatianmerupakan 2 hal utama yang harus dimiliki oleh seorang mahasiswa sebelum ia dapat mengkognisikan pengetahuan melalui proses belajar. Berhasil atau tidaknya pengetahuan tersebut diperoleh dan disimpan, baik dalam jangka waktu singkat atau lama, sangat bergantung pada proses kognitif yang dialami oleh mahasiswa. Berdasarkan hal tersebut, penelitian yang dilakukan ini berfokus pada pengukuran faktor motivasi, perhatian, serta proses kognitif yang dimiliki oleh mahasiswa itu sendiri selama menjalani proses belajar.

\section{METODE}

Penelitian ini adalah penelitian kuantitatif dengan rancangan penelitian survey. Sampel adalah 80 mahasiswa baru tahun akademik 2010/2011. Instrumen Archer's Health Professions Motivation Survey (cit. Perrotet al.) ${ }^{7}$ yang dalam penelitian ini telah dimodifikasi digunakan untuk mengukur variabel motivasi berprestasi. Untuk mengukur variabel perhatian, digunakan instrumen Adult Attention Deficiency/Hyperactivity Disorder (ADHD) diadaptasi dari http://psychentral.com. ${ }^{8}$ Instrumen ADHD ini merupakan instrumen dalam bentuk rating scale yang digunakan untuk screening awal kemampuan orang dewasa dalam mengalokasikan perhatian (attention). Untuk mengukur proses kognitif pada mahasiswa, peneliti menggunakan instrumen Cognitive Processing Inventory (CPI). CPI merupakan instrumen dalamb entuk rating scale yang digunakan sebagai bentuk penilaian formal dan screening awal untuk mengevaluasi karakteristik individu dalam pemrosesan informasi. Normalitas data akan diukur dengan menggunakan uji Kolmogorov-Smirnov. Validitas dan reliabilitas data diukur menggunakan uji korelasi Pearson Product Moment dan nilai koefisien Alfa Cronbach. Identifikasi hubungan variabel motivasi berprestasi dengan proses kognitif menggunakan uji korelasi Pearson Product Moment, demikian pula dalam mengidentifikasi hubungan variabel perhatian dengan proses kognitif.

\section{HASIL DAN PEMBAHASAN}

\section{Karakteristik Mahasiswa}

Hasil pengumpulan, pengolahan, dan analisis data pada 80 mahasiswa tingkat I semester 1 Jurusan Kesehatan Lingkungan Poltekkes Maluku T.A. 2010/2011, menunjukkan bahwa distribusi mahasiswa berdasarkan jenis kelamin sebagian besar adalah wanita yaitu sebanyak 42 orang $(52,5 \%)$. Sedangkan berdasarkan umur, mahasiswa berada pada rentang umur antara 1720 tahun yaitu sebanyak 70 orang $(87,5 \%)$. Oleh Jean Piaget (cit.Ormrod) ${ }^{10}$ dalam teori tahap perkembangan kognitif manusia sejak lahir hingga dewasa, bahwa pada umur 11 atau 12 tahun hingga dewasa, manusia

mengalami suatu tahap perkembangan kognitif yang disebut formal operations, pada tahap ini manusia dapat berpikir secara logis bila dihadapkan pada sebuah abstrak, hipotesis, atau situasi yang kontras dengan fakta, 
mereka memiliki banyak kemampuan untuk lebih mengembangkan penalarannya.

\section{Motivasi Berprestasi}

Hasil pengukuran motivasi berprestasi mahasiswa dengan menggunakan instrumen Archer's Health Professions Motivation Survey (AHPMS) yang telah dimodifikasi (Tabel 1), memperlihatkan bahwa sebagian besar mahasiswa berorientasi pada pemenuhan persyaratan akademik (rerata skor $=22,4$ ), disusul dengan orientasi belajar tuntas $($ rerata skor $=19,6)$, dan orientasi penampilan (rerata skor $=18,4)$. Hal ini mungkin saja dikarenakan pilihan jalur pendidikan ini bukanlah minat utamanya, sehingga ia hanya sekedar ingin meneruskan pendidikan tinggi demi masa depan yang lebih baik jika dibandingkan apabila ia tidak menempuh pendidikan tinggi sama sekali.

Selain faktor tersebut, ada beberapa faktor lain yang dapat melatarbelakangi rendahnya motivasi dengan orientasi belajar tuntas. Dalam studi yang dilakukan oleh Gibney ${ }^{11}$ untuk mahasiswa tahun pertama di University College Dublin, Irlandia, menemukan bahwa motivasi utama mereka untuk masuk ke perguruan tinggi adalah untuk mendapatkan prospek kerja di masa depan. Selain itu terdapat pula alasan ingin mendapatkan kesempatan untuk aktif di kehidupan secara sosial, memenuhi harapan orang tua, atau menganggap bahwa kuliah di pendidikan tinggi merupakan hal normal yang harus dilakukan seseorang dalam hidupnya.

Hasil analisis korelasi antara variabel motivasi berprestasi dengan proses kognitif menggunakan uji korelasi Pearson (Tabel 2), menunjukkan bahwa nilai $r$ hitung untuk orientasi belajar tuntas (mastery learning) dan penampilan (performance) adalah 0,304 dan 0,338, artinya ada hubungan yang bermakna antara orientasi belajar tuntas dan penampilan dengan proses kognitif mahasiswa. Hasil analisis korelasi juga memperlihatkan bahwa untuk motivasi berprestasi dengan orientasi pemenuhan persyaratan akademik (academic alienation) tidak memiliki hubungan yang bermakna, dimana nilai $r$ hitung $=0,007$, artinya tidak ada hubungan yang bermakna antara motivasi berprestasi yang berorientasi pemenuhan persyaratan akademik dengan proses kognitif.

Tabel 1. Rerata skor motivasi berprestasi berdasarkan orientasi belajar pada mahasiswa tingkat I semester 1 Jurusan Kesehatan Lingkungan Poltekkes Maluku tahun ajaran 2010/2011

\begin{tabular}{llc}
\hline & Motivasi Berprestasi & Rerata skor \\
\hline 1 & Belajar tuntas & 19,6 \\
2 & Penampilan & 18,4 \\
3 & Memenuhi persyaratan akademik & 22,4 \\
\hline & Jumlah & 60,4 \\
\hline
\end{tabular}

Sumber: Data primer

Tabel 2. Pearson correlation antara motivasi berprestasi dengan proses kognitif mahasiswa tingkat I semester 1 Jurusan Kesehatan Lingkungan Poltekkes Maluku tahun ajaran 2010/2011

\begin{tabular}{clcc} 
No & \multicolumn{1}{c}{ Motivasi Berprestasi } & $\begin{array}{c}\text { Proses } \\
\text { kognitif }\end{array}$ & $\begin{array}{c}\text { Significant } \\
\text { (2-tailed) }\end{array}$ \\
1 & Belajar tuntas (mastery learning) & $0,31^{*}$ & 0,01 \\
2 & Penampilan (performance) & $0,34^{*}$ & 0,01 \\
3 & Memenuhi persyaratan akademik (academic alienation) & 0,01 & 0,95 \\
\hline
\end{tabular}

${ }^{*}$ Hubungan bermakna $(\mathrm{p}<0,01)$ 
Motivasi merupakan salah satu faktor penting yang mendorong terjadinya proses belajar. Motivasi ini dapat terjadi baik secara intrinsik maupun secara ekstrinsik, ${ }^{12}$ dalam kasus ini, mahasiswa sebagian besar belajar karena sekedar untuk memenuhi persyaratan akademik. Bila demikian terjadi maka mahasiswa dalam proses belajarnya cenderung untuk belajar seadanya serta tidak peduli berapa nilai yang diperoleh atau materi yang dapat dipahaminya selama ia dapat lulus pada mata kuliah tersebut. Berbeda halnya dengan mahasiswa yang belajar karena memang ingin mendalami sesuatu hal baru yang menarik rasa ingin tahunya atau hanya sekedar ingin terlihat pandai diantara teman-teman sekelasnya. Pada mahasiswa dengan orientasi belajar tuntas, maka ia cenderung untuk berusaha keras dalam belajar, selalu ingin tahu dan menggali lebih dalam materi yang ia dapatkan. Sifat inilah yang akhirnya akan mendorong perkembangan proses kognitif mahasiswa.

Walaupun tidak semaksimal orientasi belajar tuntas, akan tetapi orientasi penampilan dapat pula mendorong perkembangan proses kognitif mahasiswa. Mahasiswa dengan orientasi ini memiliki keinginan untuk tampak menonjol diantara teman sekelasnya, memperoleh nilai yang bagus, atau keinginan untuk terhindar dari hukuman atau kegagalan dalam belajar, sehingga sering membuat mereka tertekan dan tidak siap bila menghadapi kegagalan. Keinginan untuk tampil baik atau mendapatkan pengakuan dari teman sekelas mendorong mahasiswa untuk berusaha belajar walau tidak maksimal (belajar secara surface dan tidak secara mendalam) untuk mencapai sesuatu dalam proses belajarnya agar tidak sampai mengalami kegagalan.

\section{Perhatian dalam Belajar}

Variabel perhatian (attention) pada mahasiswa diukur menggunakan instrumen Attention Deficit/ Hyperactivity Disorder (ADHD). Hasil pengukuran memperlihatkan bahwa seluruh mahasiswa tingkat I semester 1 Jurusan Kesehatan Lingkungan Poltekkes Maluku memiliki kesulitan dalam mengalokasikan perhatian (Attention Deficit/Hyperactivity Disorder atau Attention Deficit Disorder). Bahkan sebagian besar mahasiswa (46,3\%) mengalami ADHD kategori sedang (Tabel 3).

Tabel 3. Distribusi frekuensi skor perhatian (attention) belajar mahasiswa tingkat I semester 1 jurusan kesehatan lingkungan Poltekkes Maluku tahun ajaran 2010/ 2011 (berdasarkan hasil screening awal ADHD)

\begin{tabular}{ccccc} 
No & Intcrval skor & $\begin{array}{c}\text { Katcgori } \\
\text { ADHD }\end{array}$ & N & Jumlah \\
\hline 1 & $0-24$ & Tidak ada & 0 & 0 \\
2 & $25-34$ & Tanda awal & 3 & 3,8 \\
3 & $35-49$ & Ringan & 13 & 16,3 \\
4 & $50-69$ & Sedanl & 37 & 46,3 \\
5 & $\geq 70$ & Berat & 27 & 33,8 \\
& Jumlah & & 80 & 100 \\
\hline
\end{tabular}

Sumber: Data primer

Attention deficit/ hyperactivity disorder (ADHD) atau yang lebih sering disebut attention deficit disorder (ADD) memberikan perhatian. Penyebab munculnya masalah ini belum dipastikan, serta sering disandingkan dengan masalah kecemasan, ketidakmampuan dalam belajar, serta kesulitan untuk mendengar atau berbicara. Individu yang mengalami kesulitan dalam memperhatikan cenderung sulit untuk berkonsentrasi dan tetap fokus, serta sulit mengorganisir apa yang ada di pikiran maupun yang akan dilakukan. ${ }^{13}$
Pada penelitian ini teridentifikasi bahwa sebagian besar mahasiswa yang mengalami kesulitan dalam memfokuskan perhatian jugamemiliki kelemahan proses kognitif. Seperti telah dikemukakan sebelumnya bahwa kesulitan dalam memperhatikan juga terkait dengan ketidakmampuan dalam belajar atau learning disability, ${ }^{13}$ sehingga walaupun mahasiswa telah berusaha menjawab pertanyaan-pertanyaan pada soal pilihan ganda dengan mengingat, memahami, dan menerapkan $(\mathrm{C} 1, \mathrm{C} 2$, dan C3), akan tetapi jawaban yang diberikan belum sesuai. Hal ini terbukti dengan hubungan yang bermakna antara perhatian dengan proses kognitif (Tabel 4). 
Tabel 4. Hubungan antara perhatian dengan proses kognitif pada mahasiswa tingkat I semester 1 jurusan kesehatan lingkungan Poltekkes Maluku tahun ajaran 2010/2011 (uji korelasi Pearson)

\begin{tabular}{ccc} 
Variabel & Pearson correlation $(r)$ & Significant (2-tailed) \\
\hline Perhatian (attention) dengan Proses Kognitif & $0,26^{*}$ & 0,02 \\
\hline
\end{tabular}

${ }^{*}$ Hubungan bermakna $(\mathrm{p}<0,05)$

Dalam teori modal model of memory oleh Baddeley (cit. Lefrançois), ${ }^{14}$ disebutkan bahwa agar informasi yang diterima secara sensori tersimpan dalam working memory membutuhkan adanya perhatian. Individu memerlukan adanya perhatian untuk dapat memperbaiki retensi dan pemanggilan memori. Seseorang sulit mengingat bila ia tidak mempelajari dan ia tidak dapat mempelajari sesuatu (sehingga terjadi encode dalam otak) bila ia tidak memperhatikannya. Diperlukan perhatian/fokus 8 detik untuk memproses informasi ke dalam hipokampus, kemudian menuju pusat memori yang sesuai. ${ }^{15}$

Dengan memberikan perhatian maka mahasiswa dapat mengasimilasikan materi ke dalam bentuk yang dapat dipahami oleh kognitifnya. Sebagaimana disebutkan sebelumnya bahwa kualitas sebuah proses pembelajaran ditentukan besar kecilnya perhatian yang diberikan oleh mahasiswa. Perhatian yang baik akan memudahkan transfer informasi dan ilmu pengetahuan dari pengajar ke mahasiswa, dengan perhatian pula maka mahasiswa akan mudah untuk mengingat dan memahami informasi yang diterimanya dan kemudian menyimpannya dalam bentuk working memory.

Kualitas sebuah proses belajar ditentukan oleh besarnya perhatian yang diberikan oleh mahasiswa, sehingga bila terdapat masalah akan sangat berpengaruh terhadap pencapaian tujuan belajar serta kompetensi akhir yang ingin dicapai. Sangat penting bagi setiap pengajar untuk tetap membuat mahasiswa fokus pada materi ajar, terutama adalah dengan menciptakan lingkungan belajar yang mendukung serta memotivasi mahasiswa untuk tetap fokus dalam belajar.

Banyak metode yang dapat digunakan untuk menarik perhatian belajar mahasiswa, diantaranya adalah dengan pembelajaran yang bermakna (meaningful learning) misalnya, metode belajar kolaboratif yang menekankan pada adanya kerja sama dalam belajar (diskusi kelompok kecil dan role play), pembelajaran berbasis kasus/masalah yang menekankan pada penalaran ilmiah mahasiswa dalam mengatasi suatu masalah, atau metode belajar aktif dan mandiri yang menekankan pada peran aktif mahasiswa untuk terlibat secara langsung menggali materi belajar yang diberikan. Sebagaimana dikemukakan oleh Ormrod, ${ }^{10}$ bahwa dalam proses transfer informasi dan ilmu pengetahuan, belajar secara bermakna lebih memudahkan proses transfer tersebut jika dibandingkan dengan hanya menghafalkan materi saja. Melalui pembelajaran yang bermakna perhatian mahasiswa dalam proses belajar dapat juga dipacu dengan melibatkan mahasiswa secara aktif (student engagement). Keterlibatan mahasiswa ini penting karena kualitas pembelajaran sebagian besar tergantung pada ketertarikan mahasiswa serta kemampuan pengajar untuk menciptakan lingkungan belajar yang dapat memotivasi mahasiswa.

\section{Proses Kognitif Mahasiswa}

Hasil pengukuran menggunakan Cognitive Processing Inventory sebagaimana tampak pada Tabel 5 menunjukkan bahwa dari keseluruhan mahasiswa yang memiliki gejala ADHD, umumnya memiliki kelemahan pada area conceptual processing (26 orang) dan auditory processing (23 orang). Sedangkan yang paling sedikit adalah pada area sequential processing (1 orang). Kelemahan pada area kognitif ini terjadi dalam tingkat sedang (moderate concern) dan berat(severe concern), baik yang terjadi secara individual dalam diri mahasiswa (intracognitive), maupun bila dibandingkan dengan anggota lain dalam kelompoknya (intercognitive). 
Tabel 5. Analisis tingkat kelemahan proses kognitif mahasiswa tingkat I semester 1 jurusan kesehatan lingkungan Poltekkes Maluku tahun ajaran 2010/2011

\begin{tabular}{|c|c|c|c|c|c|c|}
\hline \multirow[b]{2}{*}{ No } & \multicolumn{6}{|c|}{ ADHD } \\
\hline & $\begin{array}{c}\text { Area proses } \\
\text { kognitif }\end{array}$ & $\begin{array}{c}\text { 'Ianda } \\
\text { Awal } \\
\text { (3 Orang) }\end{array}$ & $\begin{array}{c}\text { Ringan } \\
\text { (13 Orang) }\end{array}$ & $\begin{array}{c}\text { Sedang } \\
\text { (37 Orang) }\end{array}$ & $\begin{array}{c}\text { Berat } \\
(27 \\
\text { Orang })\end{array}$ & Concern \\
\hline 1 & $\begin{array}{l}\text { Auditory } \\
\text { processing }\end{array}$ & & $\begin{array}{l}2\left(M^{*}\right) \\
1\left(M^{* *}\right)\end{array}$ & $\begin{array}{l}7\left(M^{*}\right) \\
2\left(M^{* *}\right) \\
2\left(M^{* * *}\right) \\
1\left(S^{*}\right)\end{array}$ & $8\left(M^{*}\right)$ & 23 \\
\hline 2 & Visual processing & & $\begin{array}{l}1\left(M^{*}\right) \\
1\left(M^{\wedge \wedge}\right)\end{array}$ & $1\left(M^{*}\right)$ & $1\left(M^{*}\right)$ & 4 \\
\hline 3 & $\begin{array}{l}\text { Sequential } \\
\text { processing }\end{array}$ & & & $1\left(M^{* *}\right)$ & & 1 \\
\hline 4 & $\begin{array}{l}\text { Conceptual } \\
\text { processing }\end{array}$ & $1 \mathrm{M}^{*}$ & $1\left(M^{*}\right)$ & $\begin{array}{l}4\left(M^{*}\right) \\
1\left(M^{* *}\right) \\
7\left(M^{\star \wedge}\right) \\
2\left(S^{*}\right)\end{array}$ & $\begin{array}{l}8\left(\mathrm{M}^{*}\right) \\
1\left(\mathrm{~S}^{*}\right) \\
1\left(\mathrm{~S}^{\wedge \wedge}\right)\end{array}$ & 26 \\
\hline 5 & Processing speed & $1 \mathrm{M}^{* * *}$ & $3\left(\mathrm{M}^{*}\right)$ & $\begin{array}{l}3\left(M^{*}\right) \\
3\left(M^{* *}\right)\end{array}$ & $\begin{array}{l}2\left(M^{*}\right) \\
3\left(M^{* *}\right)\end{array}$ & 15 \\
\hline 6 & $\begin{array}{l}\text { Executive } \\
\text { processing }\end{array}$ & & $\begin{array}{l}2\left(M^{*}\right) \\
1\left(M^{\wedge}\right)\end{array}$ & $\begin{array}{l}1\left(M^{*}\right) \\
1\left(M^{\wedge}\right)\end{array}$ & & 5 \\
\hline & No concern & 1 & 6 & 16 & 11 & \\
\hline $\begin{array}{l}\text { Kete } \\
M= \\
S=S\end{array}$ & $\begin{array}{l}\text { ngan : } \\
\text { oderate concern } \\
\text { ere concern }\end{array}$ & $\begin{array}{ll}* & =I \\
* * & =I 1\end{array}$ & $\begin{array}{l}\text { acognitive } \\
\text { cognitive }\end{array}$ & $\begin{array}{r}* * *= \\
\text { Inte }\end{array}$ & $\begin{array}{l}\text { lcognitive } 8 \\
\text { ognitive }\end{array}$ & \\
\hline
\end{tabular}

Mahasiswa tingkat I semester 1 Jurusan Kesehatan Lingkungan Poltekkes Maluku memiliki kesulitan dalam mengalokasikan perhatian. Hal ini terlihat pada hasil screening awal denganmenggunakan instrumen Attention Deficit/ Hyperactivity Disorder (ADHD). Bahkan sebagian besarnya berada pada kategori sedang (46,3\%). Kesulitan dalam mengalokasikan perhatian ini akhirnya berdampak pada proses kognitif yang dimiliki. Hasil pengukuran proses kognitif dengan menggunakan instrumen Cognitive Processing Inventory (CPI), memperlihatkan bahwa sebagian besar mahasiswa yang mengalami ADHD sebagian besar memiliki kelemahan pada area conceptual processing dan auditory processing.

Perhatian yang diberikan saat belajar akan sangat membantu memori kerja (working memory) mahasiswa.
Mereka menemukan bahwa kapasitas working memory individu dapat dirangsang bila mahasiswa memberikan perhatian berdasarkan ciri/sifat yang dikombinasikan dengan perhatian spasial (tempat/lokasi). ${ }^{16}$

\section{KESIMPULAN}

Motivasi berprestasi yang berorientasi pada pembelajaran tuntas (mastery learning) dan penampilan (performance) memiliki hubungan dengan proses kognitif yang dimiliki mahasiswa. Hal tersebut menunjukkan bahwa dengan memberikan motivasi di awal proses belajar akan mendorong mahasiswa untuk mengetahui dan memahami materi ajar.

Faktor lain yang jugamemiliki hubungan dengan proses kognitif mahasiswa adalah perhatian dalam belajar. 
Semakin besar perhatian akan memudahkan mahasiswa dalam mengingat materi tersebut. Terkait hal tersebut, beberapa metode dapat digunakan untuk menarik perhatian belajar mahasiswa, diantaranya adalah pembelajaran bermakna (meaningful learning) misalnya, belajar kolaboratif yang menekankan pada adanya kerjasama dalam belajar (diskusi kelompok kecil dan role play), pembelajaran berbasis kasus yang menekankan pada penalaran ilmiah mahasiswa dalam mengatasi suatu masalah, atau metode belajar aktif mandiri yang menekankan pada peran aktif mahasiswa untuk terlibat secara langsung menggali materi belajar yang diberikan.

\section{DAFTAR PUSTAKA}

1. D'Eon MF. Knowledge loss of medical students on first year basic science courses at the University of Saskatchewan. BMC Med Educ. 2006;14(6):5.

2. Huitt W. Motivation to learn: an overview. Educational Psychology Interactive Valdosta State University; 2001 [diakses tanggal 10 Desember 2010]. Available from: http://www.edpsycinteractive.org/ topics/motivation/ motivate.html.

3. Suprijanto H. Pendidikan orang dewasa: dari teori hingga aplikasi. Jakarta: Bumi Aksara; 2009.

4. Elias H, Rahman WRA. Achievement motivation of university students. Journal of Social Science \& Humanity. 1995;3(1):1-10.

5. Perrot LJ, Deloney LA, Hastings JK, Savell S. Measuring student motivation in health professions' colleges. Advances in Health Sciences Education. 2001;6:193-203.

6. Jiang Y, Chun MM. Selective attention modulates implicit learning. The Quarterly Journal of Experimental Psychology. 2001;54A(4):1105-24.
7. Perrot LJ, Deloney LA, Hastings JK, West DS. Pharmacy student motivation: phase 1 of a longitudinal study. American Journal of Pharmaceutical Education. 2001;65:254-8.

8. Jasper L, Goldberg I. Attention deficit disorder (ADHD) test. Jasper/ Goldberg adult ADD/ ADHD screening quiz. 2010 [diakses tanggal 8 Desember 2010]. Available from: http:// www.psychentral.com/ addquiz.htm

9. Crouse SL. The cognitive processing inventory (CPI). LD Info Publishing; 2010.[diakses tanggal 6 Januari 2011]. Available from: http://www.ldinfo.com/ cpi1.htm

10. Ormrod JE. Human learning. 5th ed. New Jersey: Pearson Prentice Hall; 2009.

11. Gibney A, Moore N, Murphy F, O'Sullivan S. The first semester of university life: will I be able tomanage it at all? High Educ. 2010;62(3):351-66.

12. Woolfolk A. Educational psychology: active learning edition (part 2). 10th ed. Boston: Pustaka Pelajar (dibawah lisensi Pearson Education Inc.); 2009.

13. Bussing R, Grohol JM. Attention deficit disorder: an introduction to ADD/ADHD. 2011 [diakses tanggal 29 Mei 2011]. Available from: http:// www.psychentral.com/addconditions.htm

14. Lefrançois GR. Psychology for teaching. 10th ed. Belmont, CA: Wadsworth (a Division of Thomson Learning); 2000.

15. Emilia O. Tips meningkatkan retensi memori. Jurnal Pendidikan Kedokteran dan Profesi Kesehatan Indonesia. 2008;3(1):1-3.

16. Bengson JJ, Mangun GR, Mazaheri A. Individual working memory capacity is uniquely correlated with feature-based attention when combined with spatial attention. Attention Perception Psychophysics. 2011;73:86-102. 